\title{
Analysis of risk factors affecting coagulopathy after donor hepatectomy in a newly established liver transplant center
}

\author{
Sema Aktaș ${ }^{1}$, Șinasi Sevmiș ${ }^{1}$, Mehmet Șeker², Esin Korkut ${ }^{3}$, Hamdi Karakayalı
}

\section{ABSTRACT}

Cite this paper as: Aktaş S, Sevmiş Ş, Şeker M, Korkut E, Karakayalı H. Analysis of risk factors affecting coagulopathy after donor hepatectomy in a newly established liver transplant center. Turk J Surg 2017; 33(2): $69-75$

'Department of General Surgery, Medipol University School of Medicine, İstanbul, Turkey ${ }^{2}$ Department of Radiology, Medipol University School of Medicine, İstanbul, Turkey ${ }^{3}$ Department of Gastroenterology, Medipol University School of Medicine, İstanbul, Turkey

Address for Correspondence Şinasi Sevmiş e-mail:sinasi.sevmis@medipol.com.tr

Received: 08.09.2015 Accepted: 21.11.2015

\section{oCopyright 2017} by Turkish Surgical Association

Available online at www.turkjsurg.com
Objective: As might be expected, living donor liver surgery is associated with serious morbidity and mortality risks. Coagulopathy after donor hepatectomy is an important risk factor affecting morbidity. In this study, risk factors affecting the development of coagulopathy after donor hepatectomy was evaluated in a newly-established liver transplant center.

Material and Methods: A retrospective evaluation of 46 liver donors to whom hepatectomy was applied in Medipol Universty of School of Medicine Department of Organ Transplantation between April 2014 and July 2015 was made. Coagulopathy was defined as prothrombin time $\geq 15 \mathrm{sec}$. or platelet count $<80000 / \mathrm{mm}^{3}$ on postoperative day 3 . Donors were separated into 2 groups as those with $(n=24)$ and without $(n=22)$ coagulopathy. Preoperative, intraoperative and postoperative factors acting on coagulopathy were analyzed.

Results: In the intergroup analysis, it was seen that remnant liver volume, remnant liver volume \% and remnant liver volume to body weight ratio were factors associated with coagulopathy. The cut-off values for these 3 parameters were calculated as $773.5 \mathrm{~cm}^{3}, 40.5 \%$ and $0.915 \mathrm{~cm}^{3} / \mathrm{kg}$, respectively. Only remnant liver volume \% was determined as a risk factor for coagulopathy after donor hepatectomy on multiple logistic regression analysis.

Conclusion: The results of this study showed that the most important risk factors affecting coagulopathy after donor hepatectomy were the parameters associated with remnant liver volume.

Keywords: Donor hepatectomy, coagulopathy, remnant liver, risk factors

\section{INTRODUCTION}

Liver transplant is a lifesaving treatment in end-stage acute and chronic liver failures, primary and secondary tumors of the liver, some metabolic diseases and post-traumatic massive liver injuries. Patients stay on the waiting lists for a long time due to the shortage in cadaveric donor organs, and may even die on the waiting list. In order to overcome this problem, living donor liver transplant (LDLT) has been commonly accepted worldwide. However, protecting the donor's health should always be the most important target in LDLT (1). Coagulopathy after major hepatic resections is an important risk factor that has an impact on postoperative morbidity $(2,3)$. This becomes more of an issue particularly in the planning of interventions such as epidural catheter removal, which may be risky in terms of bleeding. In this study, the risk factors affecting the development of coagulopathy after donor hepatectomy in a newly established liver transplant center were analyzed.

\section{MATERIAL AND METHODS}

Following the necessary legal preparations and inspections, Medipol Universty School of medicine Department of General Surgery was licensed to perform liver transplantations (license no 5064) by the Ministry of Health on 03.02.2014. The liver transplantation program was started on April 2014 and from that date to July 2015, 46 LDLT were performed in our center. Donors were accepted as temporarily coagulopathic when the prothrombin time was (PT) $\geq 15 \mathrm{sec}$. or the platelet count was $<80000 / \mathrm{mm}^{3}$ on postoperative day 3 (4). According to these findings, donors were categorized as those with $(n=24)$ and without $(n=22)$ coagulopathy. This research was conducted according to the principles of the World Medical Association Declaration of Helsinki "Ethical Principles for Medical Research Involving Human Subjects".

All relevant data during preoperative preparation, operation, postoperative follow-up and control periods of the donors were recorded systematically by the same physician. These data included donor age, gender, body mass index (BMI), biopsy findings (hydrops, sinusoidal dilatation, pigment accumulation, inflammatory infiltration, parenchymal focal necrosis, microvesicular steatosis, and macrovesicular steatosis), graft type, volumetric analysis of the liver calculated by multi-slice computerized tomography (CT) [total liver volume (TLV), functional liver volume (FLV), graft volume (GV), remnant liver volume 
$(R L V)$, percentage of remnant liver volume to total liver (RLV\%), remnant liver to donor body weight ratio (RLBWR) ], graft weight after hepatectomy (GW), peri-operative use of blood transfusion, fresh frozen plasma (FFP), amounts of crystalloid and colloid solutions, operation time, as well as intraoperative and postoperative complications. Philips Brillance ICT256-slice scanner system was used for visualization, assessment and quantification of the liver that is extracted from abdominal CT images specifically providing quantitative measurements of the liver volume, including blood supply and abnormalities within the liver. It also provides information of FLV by automatically removing vascular structure's volume from total liver volume. The RLV value was calculated on CT by extracting the volume of the liver lobe to be used as the graft from the total liver volume, and RLBWR was calculated as the ratio of RLV, as detected by $\mathrm{CT}$, to body weight.

\section{Donor Preparation}

In our center, donor preparation starts with taking a detailed medical history and physical examination and progresses gradually to invasive tests. Mentally competent individuals between the ages of 18 and 65 years are accepted as donor candidates. According to the organ transplant laws of our country, the donor must be related to the recipient up to the $4^{\text {th }}$ degree or his/her spouse, and if there is no such relationship then approval from the Ethics Committee of the Local Health Authority is required. There must be no compromise of the principles stating that there must be no pecuniary advantage in the relationship between the recipient and donor, and the donor must submit into the arrangement voluntarily without being under any sort of pressure.

All donors are evaluated by transplant surgeons, hepatologists, cardiologists, pulmonologists, and psychiatrists, female donors are also evaluated by gynecologists. In the first evaluation, all risks entailed in the donor surgery, operation and postoperative follow-up are explained in detail to the donor by the transplant surgeon. The parenchymal structure of the liver, the liver volume and vascular system, and the biliary system are analyzed thoroughly by ultrasound, CT and MRI, respectively. The donor is accepted when the RLV\% is $\geq 35 \%$, RLBWR is $\geq 0.6$ and above, and the graft weight to recipient weight ratio (GBWR) is $\geq 0.8$ and above. Regardless of the RLV\%, a donor is not accepted if RLBWR is $<0.6$. The histopathologic appearance of the liver structure must be normal in liver biopsy.

\section{Donor Surgical Procedure}

Informed consent forms are received from all donors before the operation. Following anesthesia induction, $2 \mathrm{gr}$. of $2^{\text {nd }}$ generation cephalosporin is used for prophylactic purposes. During the operation, the donors are monitored through electrocardiography, invasive blood pressure obtained from a catheter placed into the radial artery, central venous pressure obtained from the right internal jugular vein, and body temperature. Bilateral or right subcostal incisions extending from the midline to the xiphoid are performed for the operation. Vascular structures in the hilus are dissected following mobilization of the liver. Inferior hepatic veins with diameters $>5 \mathrm{~mm}$ are dissected in a way to be anastomosed to the vena cava inferior, and veins with diameters $<5 \mathrm{~mm}$ are transected with ligation. The biliary tract is defined with intraoperative cholangiography and cholecystectomy is performed. The demarca- tion line is determined by placing a temporary clamp on the hepatic artery and portal vein of the lobe to be removed in order to determine the right and left lobe resection lines. For the left lateral segment, this line is determined as the right side of the falciform ligament that is to remain on the graft. Dissection is performed so that the middle hepatic vein always remains on the left lobe. In right lobe grafts, veins draining segments 5-8 to the hepatic vein are dissected and preserved to be able to make a reconstruction if they are $>5 \mathrm{~mm}$ in diameter. Cavitron ultrasonic surgical aspirator (CUSA System 200 Macrodissector; Cavitron Surgical Systems, Stamford, CT, USA) is used for parenchymal dissection.

Following completion of parenchymal dissection, the biliary tract is checked again for leakage via the cystic duct. Then the hepatic artery, portal vein and hepatic vein of the graft to be received are clamped and cut and the graft is transported to the back-table for the preservation process. The remnant hepatic vein stump is closed with $4 / 0$, and the remnant portal vein, hepatic artery and biliary tract are closed with $6 / 0$ monofilament non-absorbable suture materials. The incision is closed in layers by placing a drainage catheter in the subhepatic region.

\section{Postoperative Follow-up}

Following extubation, the donor is transferred to the intensive care unit and monitored for 1 night. After recovering consciousness, the naso-gastric catheter is removed and oral liquid nutrition is started. The donor is mobilized after 6 hours. The urinary catheter is removed on the $1^{\text {st }}$ postoperative day and the central venous catheter on the $3^{\text {rd }}$ day on condition that the platelet count is $80000 / \mathrm{mm}^{3}$ or above. Following 48 hours of controlled analgesia, oral analgesic agents are administered. Liver function tests are checked daily during the hospitalization period. The drainage tube is removed when the daily amount of serous drainage is $<100 \mathrm{cc}$. Donors are generally discharged on the $4^{\text {th }}-7^{\text {th }}$ postoperative day. Follow-up examinations are made in 1 week after discharge, then at the $1^{\text {st }}, 3^{\text {rd }}, 6^{\text {th }}$ and $12^{\text {th }}$ months including Doppler USG and liver function tests.

\section{Statistical Analysis}

Statistical Package for the Social Sciences version 22.0 (IBM Corp.; Armonk, NY, USA) program was used for data analysis. The Shapiro-Wilk test was used for the conformity of the data to normal distribution, and the Leneve test was used for variance homogeneity. Independent-Samples $T$ test was used with Bootstrap results and the Mann-Whitney $U$ test was used with the Monte Carlo simulation method in the comparison of two independent groups. The Pearson Chi-Square and Fisher Exact tests were performed with the Monte Carlo Simulation method in the comparison of categorical data. Odds ratio was used for the determination of the most important risk factor among categorical significant risk factors. Logistic regression test was used to determine the cause and effect relationship of categorical response variable with explanatory variables in binary and multinominal categories. The relationship between the classification of groups separated by the cut-off value calculated according to variables and the real classification, sensitivity and specifity values were analyzed and stated by ROC (Receiver Operating Curve). Quantitative data were stated as mean \pm std.(standard deviation), range (Maximum-Minimum) and median range (Maximum-Minimum) values. Categorical data were stated as number (n) and percentage (\%). The data 
were analyzed at $95 \%$ confidence level and a value of $p<0.05$ was accepted as statistically significant.

\section{RESULTS}

Seventeen of the 46 donors were (37\%) female, and 29 (63\%) were male. The mean age of the donors was $35.24 \pm 7.5$ years (25-55 years) in the group with coagulopathy, and $35 \pm 8.16$ years (23-53 years) in the group without coagulopathy. Body mass index (BMI) was $27,23 \pm 4,01(35,8-20)$ in the group with coagulopathy, and $27,12 \pm 4,11(34,4-20)$ in the group without coagulopathy. The demographic data were similar in both groups. All patients with coagulopathy were diagnosed based on a PT value $>15 \mathrm{sec}$. There were no donors with thrombocytopenia $<80,000$. There were no mortalities.

The 41 preoperative donor liver biopsies revealed 13 hydrops, 8 sinusoidal dilatation, 9 pigment deposition in hepatocytes, and 18 sparse focal necrosis. Microvesicular steatosis between 3-15\% was observed in 13 donors and macrovesicular steatosis between $5-25 \%$ in 20 donors. Parenchymal structures were normal in all donors. No significant difference was seen between the groups in terms of all the parameters. The findings are summarized in Table 1.

Per-operative blood transfusions were performed on 21 donor operations. In 2 donor operations, significant bleeding occurred due to sliding of the vascular clamp on the vena cava securing the hepatic vein stump. No significant difference was seen between the groups in terms of intraoperative blood transfusion requirements, crystalloid and colloid fluid amounts given, operation times and intraoperative complications (Table 2).

When volumetric analysis results were examined, it was seen that there was no significant difference between the groups with regards to TLV, FLV, GV and graft type. GW results were also similar. However, the parameters of RLV $\left[602 \mathrm{~cm}^{3}\right.$, (413$\left.1450 \mathrm{~cm}^{3}\right)$ versus $\left.670 \mathrm{~cm}^{3},\left(503-1469 \mathrm{~cm}^{3}\right), \mathrm{p}=0.046\right], \mathrm{RLV} \%$ [39\%, (35-80\%) versus $42.5 \%,(37-85 \%), p=0.004]$, and RLBWR $[0.79 \% / \mathrm{kg},(0.59-1.64 \% / \mathrm{kg})$ versus $0.915(0.67-1.8 \% / \mathrm{kg})$,

Table 1. Histopathologic findings of donor liver biopsies with or without coagulopathy

\begin{tabular}{|lccc|} 
& No coagulopathy $(\mathbf{n}=\mathbf{2 2})$ & Coagulopathy $(\mathbf{n = 2 4 )}$ & $\mathbf{p}$ \\
\hline Sex (female/male) & $10(45.5) / 12(54.5)$ & $7(29.2) / 17(70.8)$ & 0.361 \\
\hline Age, years & $35.00 \pm 8.16(53-23)$ & $35.25 \pm 7.50(55-25)$ & 0.914 \\
\hline BMl, kg/m² & $27.12 \pm 4.11(34.4-20)$ & $27.23 \pm 4.01(35.8-20)$ & 0.942 \\
\hline Hemoglobin, g/dL & $14.45 \pm 1.89(18-9.9)$ & $14.35 \pm 2.00(19.9-10.2)$ & 0.859 \\
\hline White Blood cell, 10e3/uL & $7.79 \pm 1.49(10.8-5.4)$ & $7.28 \pm 2.01(11.9-4.6)$ & 0.334 \\
\hline Platelet, 10e3/uL & $251.18 \pm 68.18(378-129)$ & $232.79 \pm 61.04(405-130)$ & 0.340 \\
\hline PT, s & $13.11 \pm 0.68(14.6-12.3)$ & $13.44 \pm 0.77(14.9-12.2)$ & 0.123 \\
\hline INR & $1.03 \pm 0.09(1.2-0.9)$ & $1.09 \pm 0.09(1.25-0.89)$ & 0.039 \\
\hline AST, U/L & $17(44-10.7)$ & $16(34-11)$ & 0.683 \\
\hline ALT, U/L & $17.5(54-8.6)$ & $16(60-6.9)$ & 0.891 \\
\hline Albumin & $4.56 \pm 0.38(5.3-3.5)$ & $4.47 \pm 0.26(5-4.1)$ & 0.316 \\
\hline Total Bilirubin mg/dL & $0.415(3.2-0.2)$ & $0.5(1.4-0.2)$ & 0.688 \\
\hline Direct Bilirubin mg/dL & $0.2(0.9-0.1)$ & $0.2(0.4-0.1)$ & 0.710 \\
\hline
\end{tabular}

Fisher Exact Test (Monte Carlo); Independent T Test (Bootstrap); Mann-Whitney U Test (Monte Carlo); Mean \pm Sd (standard deviation); Range (maximumminimum); Median Range (maximum-minimum); $\mathrm{n}(\%)$

BMI: Body Mass Index; PT: prothrombin time; AST: aspartate aminotransferase; ALT: alanine aminotransferase

Table 2. Intraoperative characteristics of donors with or without coagulopathy

\begin{tabular}{|lccc|}
\hline & No coagulopathy (n=22) & Coagulopathy (n=24) & $\mathbf{p}$ \\
\hline Biopsy (no/yes) & $4(18.2) / 18(81.8)$ & $1(4.2) / 23(95.8)$ & 0.178 \\
\hline Hidrops (no/yes) & $15(78.9) / 4(21.1)$ & $15(62.5) / 9(37.5)$ & 0.324 \\
\hline Sinusoidal dilatation (no/yes) & $15(83.3) / 3(16.7)$ & $17(77.3) / 5(22.7)$ & 0.709 \\
\hline Collection of pigment (no/yes) & $13(72.2) / 5(27.8)$ & $18(81.8) / 4(18.2)$ & 0.705 \\
\hline Inflammatory infiltration (no/yes) & $13(72.2) / 5(27.8)$ & $10(43.5) / 13(56.5)$ & 0.112 \\
\hline Focal Necrosis (no/yes) & $11(61.1) / 7(38.9)$ & $11(50) / 11(50)$ & 0.537 \\
\hline Microvesicular steatosis (no/yes) & $11(61.1) / 7(38.9)$ & $16(72.7) / 6(27.3)$ & 0.509 \\
\hline Macrovesicular steatosis (no/yes) & $9(50) / 9(50)$ & $11(50) / 11(50)$ & 1 \\
\hline $\begin{array}{l}\text { Fisher Exact Test (Monte Carlo) } \\
\mathrm{n}(\%)\end{array}$ & & & \\
\hline
\end{tabular}


Table 3. Multi-slice computed tomography (CT) findings of donors with or without coagulopathy

\begin{tabular}{|c|c|c|c|}
\hline & No coagulopathy $(n=22)$ & Coagulopathy ( $n=24)$ & p \\
\hline TLV & $1.616 .95 \pm 201.10(1952-1256)$ & $1.582 .29 \pm 206.55(2115-1190)$ & 0.553 \\
\hline FLV & $1.561 .05 \pm 194.59(1883-1217)$ & $1.524 .83 \pm 199.73(2050-1149)$ & 0.523 \\
\hline GV & $868(1100-236)$ & $918.5(1278-258)$ & 0.508 \\
\hline Type of graft (left/right) & $5 / 17$ & $2 / 22$ & 0.234 \\
\hline GW & $920(1050-220)$ & $935(1150-320)$ & 0.324 \\
\hline RLV & $670(1469-503)$ & $602.5(1450-413)$ & 0.046 \\
\hline RLV\% & $42.5(85-37)$ & $39(80-35)$ & 0.004 \\
\hline RLBWR & $0.915(1.8-0.67)$ & $0.79(1.64-0.59)$ & 0.034 \\
\hline \multicolumn{4}{|c|}{$\begin{array}{l}\text { Fisher exact Test (Monte Carlo); Independent T Test (Bootstrap); Mann-Whitney U Test (Monte Carlo); Mean } \pm \text { Sd (standard deviation); Range (maximum- } \\
\text { minimum); Median Range (maximum-minimum); }(\%) \\
\text { TLV: total liver volume; FLV: functional liver volume; GV: graft volume; GW: graft weight calculated intraoperatively, RLV: remnant liver volume; RLBWR: remnant } \\
\text { liver body weight ratio }\end{array}$} \\
\hline
\end{tabular}

Table 4. Analysis of factors predict coagulopathy of donor's using Roc curve with or without coagulopathy

\begin{tabular}{|c|c|c|c|}
\hline & No coagulopathy $(n=22)$ & Coagulopathy ( $n=24)$ & $\mathrm{p}$ \\
\hline TLV & $1.616 .95 \pm 201.10(1952-1256)$ & $1.582 .29 \pm 206.55(2115-1190)$ & 0.553 \\
\hline FRV & $1.561 .05 \pm 194.59(1883-1217)$ & $1.524 .83 \pm 199.73(2050-1149)$ & 0.523 \\
\hline GV & $868(1100-236)$ & $918.5(1278-258)$ & 0.508 \\
\hline Type of graft (Left/Right) & $5(22.7) / 17(77.3)$ & $2(8.3) / 22(9.7)$ & 0.234 \\
\hline GW & $920(1050-220)$ & $935(1150-320)$ & 0.324 \\
\hline RLV & $670(1469-503)$ & $602.5(1450-413)$ & 0.046 \\
\hline RLV\% & $42.5(85-37)$ & $39(80-35)$ & 0.004 \\
\hline RLBWR & $0.915(1.8-0.67)$ & $0.79(1.64-0.59)$ & 0.034 \\
\hline \multicolumn{4}{|c|}{$\begin{array}{l}\text { Fisher exact Test (Monte Carlo); Independent T Test(Bootstrap); Mann-Whitney U Test (Monte Carlo); Mean } \pm \text { Sd (standard deviation); Range (maximum- } \\
\text { minimum); Median Range (maximum-minimum); }(\%) \\
\text { TLV: total liver volume; FRV: functional liver volume; GV: graft volume; GW: graft weight which calculate intraoperatively; RLV: remnant liver volume: RLBWR } \\
\text { remnant liver body weight ratio }\end{array}$} \\
\hline
\end{tabular}

$p=0.034]$ were significantly lower in the group with coagulopathy. The findings are summarized in Table 3 and Figure 1a-c.

In the intergroup analyses, the ROC curve and cut-off values were calculated for RLV, RLV\% and RLBWR parameters, which were determined to have an effect on coagulopathy. In these analyses, the cut-off values were calculated as $773.5 \mathrm{~cm}^{3}$, $40.5 \%$ and $0.915 \% / \mathrm{kg}$, respectively, for RLV, RLV\% and RLBWR. All three values were statistically significant. The analysis results are summarized in Table 4 and Figure 2.

Remnant liver volume, RLV\% and RLBWR values, for which significant results were found in the statistical analyses performed based on the cut-off values, were analyzed again with the multiple logistic regression model. In this analysis, as summarized in Table 5, RLV\% of $<40.5 \%$ was seen as a statistically significant risk factor for the development of coagulopathy $[(p=0.01$, AUC \pm Se:0.745 \pm 0.073 , Odds Ratio (95\%C.I):0.188 (0.053-0.664)].

\section{DISCUSSION}

Liver transplant is the only curative treatment for end-stage liver failure, acute liver failure, some metabolic diseases and plants are being performed using partial grafts obtained from living donors due to the shortage of cadaveric donor organs in developing countries, such as Turkey. Living-donor liver transplantation has the advantages of shortening the waiting time, extending life expectancy and that it can be performed under elective conditions (5). LDLT requires a donor who has been tested and confirmed to be sufficiently healthy to be exposed to an operation with serious morbidity and mortality risks. Therefore, the main duty and responsibility of organ transplant surgeons are to protect the donor's health and to minimize any risks associated with the operation. Despite developments in surgical techniques and experiences, a complication rate of approximately $38 \%$ and a mortality rate of $0.2 \%$ has been reported. Fortunately, almost all donors return to their normal lives at 3-6 months postoperatively (6-8). There is a higher rate of complications and mortality in right lobe donors with a long-term negative effect on quality of life. The only reason of the higher mortality and morbidity rate in right lobe donors is the greater liver volume to be removed $(8,9)$. In the current study, 39 donors underwent right hepatectomy while 7 underwent left lobe or left lateral segment resection. Of the donors with coagulopathy, right lobectomy was applied to 22 cases and left lobe or left lateral segment hepatectomy to 2 . 

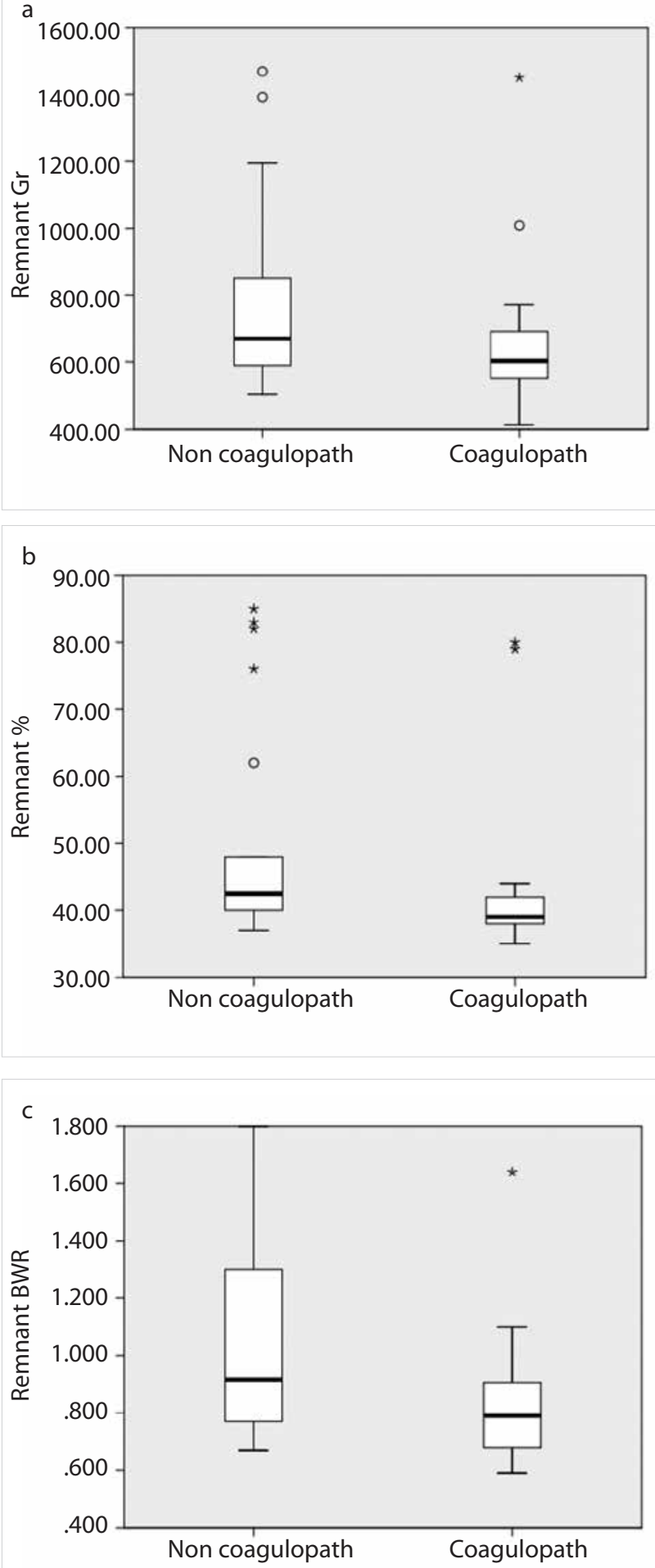

Figure 1. a-c. (a) Analysis of factors predicting coagulopathy in donor's remnant liver volume (RLV), (b) Analysis of factors predicting coagulopathy in donor's \% remnant liver volume (\%RLV), (c) Analysis of factors predicting coagulopathy in donor'sremnant volume to body weight ratio (RLBWR)

Major hepatic resection leads to a reduction in liver tissue that synthesizes coagulation factors and accordingly to the development of coagulopathy $(3,10)$. Temporary coagulopathy has been reported after resections performed for LDLT and liver tumors (4, 10-12). In these studies; hemorrhage, transfusion, temporary cessation of liver blood flow, fibrinolysis, high BMI,

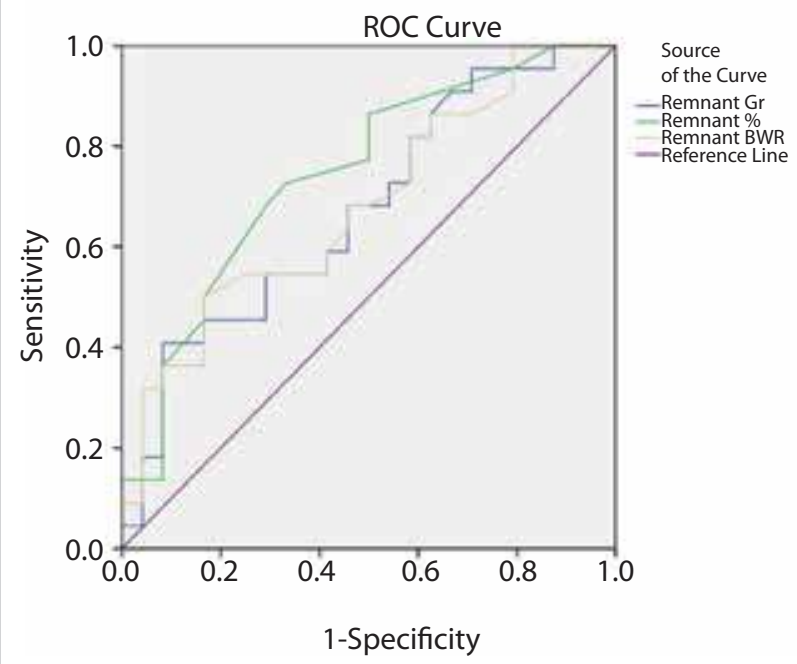

Diagonal segments are produced by ties

Figure 2. ROC curve analysis

and decrease of synthetic activity have been reported as factors affecting coagulopathy. The Pringle's maneuver used for reducing hemorrhage has been reported as an independent risk factor that affects coagulopathy (13). In the current series, there was no bleeding that required temporary occlusion of liver blood flow. RLV\% was found to be a risk factor affecting coagulopathy development.

Coagulopathy is often accepted as a situation that jeopardizes donor safety, although it is not a factor that extends length of hospital stay in donors. In these patients who undergo major surgery, perioperative monitoring is obtained by central, epidural and arterial catheters, which carry the risk of bleeding in a coagulopathic environment when they are removed. Karna et al. (3) suggested that the INR value should be $<1.5$ for the epidural catheter to be removed safely, and therefore this catheter should not be removed during the first 4 days after hepatectomy. In another study, it was reported that invasive catheters could be removed safely in cases where the platelet count is $100000 / \mathrm{mm}^{3}$ (14). In our center, epidural anesthesia is not used. The central venous catheter used for monitoring is generally removed on the $3^{\text {rd }}$ postoperative day, when the platelet count is $\geq 80000 / \mathrm{mm}^{3}$. No complications were recorded associated with the removal of the catheters.

Due to the higher volume of liver removed after right lobe donor hepatectomy, there is a higher risk of coagulopathy development as compared to left lobe procedures. Remnant liver volume measured with CT is generally stated as \%. In previous studies, it has been shown that hepatectomy could be implemented safely when the RLV is $>30 \%$, and complications have been reported to significantly increase in donors with a RLV of $<30 \%$. The same studies have also reported that the rate of coagulopathy was higher in donors with lower RLV percentages $(3,15,16)$. Fan et al. $(17)$ reported that the minimum remnant volume should be $\geq 30 \%$ for donors. In the current series, RLV $<40.5 \%$ was determined as an independent risk factor on the development of coagulopathy. In line with this data, although it has been stated that hepatectomy performed with RLV $>30 \%$ is safe, it should be kept in mind that a completely healthy individual underwent a major operation. 
Table 5. Analysis of factors predict coagulopathy of donor's using Roc curve with or without coagulopathy

\begin{tabular}{|c|c|c|c|c|c|c|}
\hline & Cut-offs & $\begin{array}{l}\text { No Coagulopathy } \\
(n=22)\end{array}$ & $\begin{array}{l}\text { Coagulopathy } \\
(n=24)\end{array}$ & $\begin{array}{l}\text { Odds Ratio } \\
\text { (95\%C.I) }\end{array}$ & $\mathrm{AUC} \pm \mathrm{Se}$ & $p$ \\
\hline INR & $\begin{array}{l}<1.035 \\
>1.035\end{array}$ & $\begin{array}{c}12(54.5)^{* *} \\
10(45.5)\end{array}$ & $\begin{array}{c}6(25) \\
18(75)^{*}\end{array}$ & $3.6(1.033-12.542)$ & $0.663 \pm 0.080$ & 0.059 \\
\hline RLV & $\begin{array}{l}<773.5 \\
>773.5\end{array}$ & $\begin{array}{l}9(40.9)^{* *} \\
13(59.1)\end{array}$ & $\begin{array}{c}2(8.3) \\
22(91.7)^{*}\end{array}$ & $7.615(1.421-40.803)$ & $0.673 \pm 0.080$ & 0.004 \\
\hline$\% R L V$ & $\begin{array}{l}>40.5 \\
<40.5\end{array}$ & $\begin{array}{c}16(72.7)^{* * *} \\
6(27.3)\end{array}$ & $\begin{array}{c}8(33.3) \\
16(66.7)^{*}\end{array}$ & $5.33(1.505-18.899)$ & $0.745 \pm 0.073$ & 0.004 \\
\hline RLBWR & $\begin{array}{l}>0.915 \\
<0.915\end{array}$ & $\begin{array}{c}11(50)^{* *} \\
11(50)\end{array}$ & $\begin{array}{c}4(16.7) \\
20(83.3)^{*}\end{array}$ & $5.0(1.283-19.490)$ & $0.683 \pm 0.079$ & 0.034 \\
\hline
\end{tabular}

Roc Curve Analysis (Youden index J - Honley\&Mc Nell)

*Sensitivity

**Specificity

${ }^{\mathrm{a}}$ significant odds ratio

AUC: area under the ROC curve; Se: standard error; C.I: confidence interval; RLV: remnant liver volume; RLBWR: remnant liver body weight ratio

In a series of 74 cases of major liver resections for liver disease, Truant et al. (18) reported that hepatectomy could safely be performed when RLV\% is $>20 \%$ and RLBWR is $>0.5$, and that liver failure and thus mortality rates were higher in cases where the values were below these levels. In another study, the cut-off value for RLBWR was stated as 0.4 in patients with liver disease (19). In a study of 83 cases, Radtke et al. (20) reported that temporary small-for-size syndrome developed in 3 living donors. The RLBWR values of those 3 patients were given as 0.6 and 0.5 . In another study, it was reported that morbidity was significantly higher when RLV\% was $<30 \%$ and RLBWR $<0.6$ (21). In our center, it is accepted that RLBWR should be $\geq 0.6$ for LDLT. In this study, the cut-off value for RLBWR was determined as 0.915 , there was determined to be a possibility of estimating coagulopathy development with $83 \%$ sensitivity. Although an extensive resection is acceptable in patients with liver disease, even with poor results, a living liver donor who is known to be completely healthy should never be jeopardized.

\section{CONCLUSION}

The most important risk factors affecting coagulopathy after donor hepatectomy are remnant liver volume and its associated parameters. It must be taken into consideration that coagulopathy is an important factor that affects donor survival and morbidity. Donor selections must be made more liberally.

Ethics Committee Approval: Authors declared that the research was conducted according to the principles of the World Medical Association Declaration of Helsinki "Ethical Principles for Medical Research Involving Human Subjects". (amended in October 2013).

Informed Consent: Informed consent was not received due to the retrospective nature of the study.

Peer-review: Externally peer-reviewed.

Author Contributions: Concept - S.A.; Design - Ş.S.; Supervision - H.K.; Resource - S.A., Ş.S.; Materials - S.A., Ş.S.; Data Collection and/or Processing - Ş.S., E.K., M.Ş.; Analysis and/or Interpretation - Ş.S.; Literature Search - S.A.; Writing Manuscript - S.A.; Critical Reviews - H.K.

Conflict of Interest: No conflict of interest was declared by the authors.

Financial Disclosure: The authors declared that this study has received no financial support.

\section{REFERENCES}

1. Clarke H, Chandy T, Srinivas C, Ladak S, Okubo N, Mitsakakis N, et al. Epidural analgesia provides better pain management after live liver donation: a retrospective study. Liver Transpl 2011; 7: 315323. [CrossRef]

2. Schindl MJ, Redhead DN, Fearon KC, Garden OJ, Wigmore SJ; Edinburgh Liver Surgery and Transplantation Experimental Research Group (eLISTER). The value of residual liver volume as a predictor of hepatic dysfunction and infection after major liver resection. Gut 2005; 54: 289-296. [CrossRef]

3. Karna ST, Pandey CK, Sharma S, Singh A, Tandon M, Pandey VK. Postoperative coagulopathy after live related donor hepatectomy: Incidence, predictors and implications for safety of thoracic epidural catheter. J Postgrad Med 2015; 61: 176-180. [CrossRef]

4. Ramspoth T, Roehl AB, Macko S, Heidenhain C, Junge K, Binnebösel $M$, et al. Risk factors for coagulopathy after liver resection. J Clin Anesth. 2014; 26: 654-662. [CrossRef]

5. Northup PG, Abecassis MM, Englesbe MJ, Emond JC, Lee VD, Stukenborg GJ, et al. Addition of adult-to-adult living donation to liver transplant programs improves survival but at an increased cost. Liver Transpl 2009; 15: 148-162. [CrossRef]

6. Patel S, Orloff M, Tsoulfas G, Kashyap R, Jain A, Bozorgzadeh A, et al. Living-donor liver transplantation in the United States: identifying donors at risk for perioperative complications. Am J Transplant 2007; 7: 2344-2349. [CrossRef]

7. Middleton PF, Duffield M, Lynch SV, Padbury RT, House T, Stanton $\mathrm{P}$, et al. Living donor liver transplantation--adult donor outcomes: a systematic review. Liver Transpl 2006; 12: 24-30. [CrossRef]

8. Sevmis S, Diken T, Boyvat F, Torgay A, Haberal M. Right hepatic lobe donation: impact on donor quality of life. Transplant Proc 2007; 9: 826-828. [CrossRef]

9. Beavers KL, Sandler RS, Shrestha R. Donor morbidity associated with right lobectomy for living donor liver transplantation to adult recipients: a systematic review. Liver Transpl 2002; 8: 110117. [CrossRef]

10. Choi SJ, Gwak MS, Ko JS, Lee H, Yang M, Lee SM, et al. The effects of the exaggerated lithotomy position for radical perineal prostatectomy on respiratory mechanics. Anaesthesia 2006; 61: 439443. [CrossRef]

11. Pelton JJ, Hoffman JP, Eisenberg BL. Comparison of liver function tests after hepatic lobectomy and hepatic wedge resection. Am Surg 1998; 64: 408-414

12. Schumann R, Zabala L, Angelis M, Bonney I, Tighiouart H, Carr DB. Altered hematologic profiles following donor right hepatectomy and implications for perioperative analgesic management. Liver Transpl 2004; 10: 363-368. [CrossRef] 
13. Yaun FS, Ng SY, Ho KY, Lee SY, Chung AY, Poopalalingam R. Abnormal coagulation profile after hepatic resection: The effect of chronic hepatic disease and implications for epidural analgesia. J Clin Anesth 2012; 24: 398-403. [CrossRef]

14. Horlocker TT, Wedel DJ, Benzon H, Brown DL, Enneking FK, Heit $\mathrm{JA}$, et al. Regional anesthesia in the anticoagulated patient: Defining the risks (the second ASRA Consensus Conference on Neuraxial Anesthesia and Anticoagulation). Reg Anesth Pain Med 2003; 28: 172-197. [CrossRef]

15. Dayangac M, Taner CB, Balci D, Memi I, Yaprak O, Akin B, et al. Use of middle hepatic vein in right lobe living donor liver transplantation. Transpl Int 2010; 23: 285-291. [CrossRef]

16. Kim YK, Shin WJ, Song JG, Jun IG, Kim HY, Seong SH, et al. Factors associated with changes in coagulation profiles after living donor hepatectomy. Transplant Proc 2010; 42: 2430-2435. [CrossRef]

17. Fan ST, Lo CM, Liu CL, Yong BH, Chan JK, Ng IO. Safety of donors in live donor liver transplantation using right lobe grafts. Arch Surg. 2000; 135: 336-340. [CrossRef]
18. Truant S, Boleslawski E, Sergent G, Leteurtre E, Duhamel A, Hebbar $M$, et al. Liver function following extended hepatectomy can be accurately predicted using remnant liver volume to body weight ratio. World J Surg 2015; 39: 1193-1201. [CrossRef]

19. Chun YS, Ribero D, Abdalla EK, Madoff DC, Mortenson MM, Wei $\mathrm{SH}$, et al. Comparison of two methods of future liver remnant volume measurement. J Gastrointest Surg 2008; 12: 123-128. [CrossRef]

20. Radtke A, Sgourakis G, Molmenti EP, Schroeder T, Cicinnati VR, Beckebaum S, et al. M. The "carving" liver partitioning technique for graft hepatectomy in live donor liver transplantation: a single-center experience. Surgery. 2013; 153: 189-199. [CrossRef]

21. Yaprak O, Guler N, Altaca G, Dayangac M, Demirbas T, Akyildiz M, et all. Ratio of remnant to total liver volume or remnant to body weight: which one is more predictive on donor outcomes. HPB (Oxford) 2012; 14: 476-482. [CrossRef] 